\title{
Coronary Artery Problems Late After Arterial Switch Operation for Transposition of the Great Arteries
}

\author{
Takeshi Tsuda, MD; Abdul M. Bhat, MD; Bradley W. Robinson, MD; \\ Jeanne M. Baffa, MD; Wolfgang Radtke, MD
}

\begin{abstract}
Background: The incidence of late coronary artery abnormalities after arterial switch operation (ASO) for d-loop transposition of the great arteries may be underestimated.
\end{abstract}

Methods and Results: We retrospectively reviewed coronary artery morphology in 40 of 97 patients who survived
the first year after ASO. Seven asymptomatic patients developed significant late coronary artery abnormalities. One
patient died suddenly at home with severe left coronary artery (LCA) ostial stenosis at age 3.8 years. The second
patient collapsed during exercise at age 9.6 years due to ventricular fibrillation and severe LCA ostial stenosis despite
prior negative exercise stress test (EST) and myocardial perfusion imaging (MPI). The third patient was found to
have moderate ostial stenosis of the LCA with negative EST and MPI. The fourth patient with exercise-induced ST-T
depression and myocardial perfusion defect was shown to have complete LCA occlusion with collateral vessel forma-
tion. Three other patients had complete proximal obliteration of either of the coronary arteries with collateral supply.
An additional 4 asymptomatic patients had trivial-mild narrowing of the LCA on routine selective coronary angiogram.

Conclusions: Incidence of late coronary stenosis or occlusion was not infrequent after ASO (11.3\%) and presented usually without preceding symptoms and often after negative non-invasive screening. We advocate routine coronary imaging in all patients after ASO before they participate in competitive sports. (Circ $J$ 2015; 79: 2372-2379)

Key Words: Arterial switch operation; Coronary ostial stenosis; Myocardial ischemia; Sudden death; Transposition of the great arteries

$\mathbf{T}$ he long-term prognosis of d-loop transposition of the great arteries (d-TGA) significantly improved after the introduction of arterial switch operation (ASO) in the 1970s. ${ }^{1-6}$ Transfer of the coronary arteries during ASO is a critical surgical step that influences early postoperative outcome. Whereas coronary complications are regarded as a major risk factor for early postoperative morbidity and mortality after $\mathrm{ASO},{ }^{7-10}$ the incidence of late coronary problems after ASO is largely unknown. These patients remain generally asymptomatic, and the first manifestation of the coronary abnormality may be circulatory collapse or unexpected sudden death. ${ }^{11-13}$ Patients with severe coronary artery stenosis may be totally asymptomatic with no evidence of myocardial ischemia at rest or with exercise. ${ }^{14}$ In the majority of retrospective large cohort studies, the incidence of late coronary artery abnormalities was relatively low, $<3 \%, 4,15-17$ but others reported a higher incidence of 5-8\%, after ASO. ${ }^{718-21}$ The incidence and pathogenesis of late coronary artery abnormalities after ASO are poorly understood.

After successful ASO, patients with d-TGA are routinely evaluated in the outpatient clinic for growth and development, symptoms, exercise tolerance, and hemodynamic assessment with non-invasive tests including electrocardiogram (ECG) and echocardiogram. Exercise stress test (EST) and myocardial perfusion imaging (MPI) may be performed to assess aerobic fitness level and myocardial perfusion status. Cardiac catheterization and other imaging modalities, such as computed tomography (CT) and magnetic resonance imaging (MRI), may be indicated for assessment of existing hemodynamic and anatomical abnormalities including stenosis of anastomotic sites, branch pulmonary artery (PA) stenosis, neoaortic root enlargement, neoaortic valve regurgitation, and possible coronary artery abnormalities. ${ }^{22}$ There is no consensus, however, as to how and when coronary artery status can be reliably assessed as a long-term follow-up strategy in asymptomatic patients with d-TGA after ASO.

To investigate the reliability of clinical assessment and noninvasive tests in detecting significant coronary stenosis or total obliteration, we reviewed the medical records of all patients who were followed at Nemours Cardiac Center of Alfred I. duPont Hospital for Children, Wilmington, Delaware, USA after neonatal ASO. We examined clinical presentation at each outpatient encounter, non-invasive cardiac studies, and specific

Received May 13, 2015; revised manuscript received June 25, 2015; accepted July 9, 2015; released online August 19, 2015 Time for primary review: 29 days

Nemours Cardiac Center, Nemours/Alfred I. duPont Hospital for Children, Wilmington, DE, USA

Mailing address: Takeshi Tsuda, MD, Nemours Cardiac Center, Nemours/Alfred I. duPont Hospital for Children, 1600 Rockland Road, Wilmington, DE 19803, USA. E-mail: ttsuda@nemours.org

ISSN-1346-9843 doi:10.1253/circj.CJ-15-0485

All rights are reserved to the Japanese Circulation Society. For permissions, please e-mail: cj@j-circ.or.jp 


\begin{tabular}{|lcc|}
\hline Table 1. Patient Clinical Profile & $\mathbf{n}=97$ & $\%$ \\
Male & 63 & 64.9 \\
Anatomical classification & & \\
d-TGA/IVS & 66 & 68.0 \\
d-TGA with VSD & 23 & 22.7 \\
d-TGA with VSD and CoA/arch hypoplasia & 3 & 3.1 \\
Taussig-Bing anomaly (DORV) & 5 & 5.2 \\
d-TGA with single coronary artery & 3 & 3.1 \\
Years of follow-up & & \\
1-2 & 13 & 13.4 \\
2-5 & 18 & 18.6 \\
5-10 & 29 & 30.0 \\
10-15 & 18 & 18.6 \\
$>15$ & 19 & 19.6 \\
Tests & & \\
ECG and echocardiogram & 97 & 100 \\
EST & 30 & 30.9 \\
MPI (and EST) & 24 & 24.7 \\
cMRI & 29 & 29.9 \\
Cardiac catheterization & 70 & 72.2 \\
Coronary angiogram & 39 & 40.2 \\
Autopsy & 1 & 1.0 \\
\hline
\end{tabular}

cMRI, cardiac magnetic resonance imaging; CoA, coarctation of aorta; d-TGA, d-transposition of the great arteries; DORV, double outlet right ventricle; ECG, electrocardiogram; EST, exercise stress test; IVS, intact ventricular septum; MPI, myocardial perfusion imaging; VSD, ventricular septal defect.

imaging for coronary morphology, and assessed the incidence and presentation of late coronary abnormalities in these patients.

\section{Methods}

Retrospective chart review was performed for all 97 patients who underwent ASO for d-TGA and double outlet right ventricle (DORV; Taussig-Bing anomaly) in the newborn period and who were followed for at least 12 months at the Nemours Cardiac Center of Alfred I. duPont Hospital for Children from 1998 to 2013. Approval for the study was obtained from the Institutional Review Board at Nemours/Alfred I. duPont Hospital for Children. Seventy-one ASO were performed at the Nemours Cardiac Center (73.2\%), whereas 26 (26.8\%) were done elsewhere. The LeCompte maneuver was used in all patients to establish RV-PA continuity. The coronary ostia were excised with a large "button" of surrounding aortic wall and then reimplanted to the neoaorta except in the patients with single coronary artery who underwent Takeuchi procedure. Patients who did not survive beyond the first birthday were excluded. These 97 patients were followed regularly in the outpatient cardiology clinic with ECG and echocardiogram for more than 1 year. Echocardiograms were reviewed and finalized by each ordering cardiologist or the Echocardiography Laboratory attending of the day (overseen by J.M.B, Director of Echocardiography Laboratory). Additional diagnostic tests were performed including EST, MPI, MRI, CT/CT angiography, and/or cardiac catheterization, as clinically indicated. EST was performed using a bicycle ergometer or treadmill under the Bruce protocol. The study was reviewed and finalized by a group of cardiologists assigned to the Exercise Laboratory (overseen by B.W.R., Director of Exercise

\begin{tabular}{|lcc|}
\hline \multicolumn{2}{c|}{ Table 2. Indications for Coronary Investigation } \\
$\quad$ Indications & $\mathbf{n}=\mathbf{4 0}$ & $\%$ \\
$\begin{array}{l}\text { Investigation of abnormal hemodynamics } \\
\text { on echocardiogram }\end{array}$ & 24 & 60.0 \\
Routine assessment (sports clearance) & 7 & 17.5 \\
Symptoms & 4 & 10.0 \\
$\quad$ Chest pain & 1 & \\
Palpitations (patient 5) & 1 & \\
Sudden death-autopsy (patient 1) & 1 & \\
Cardiac arrest/VF* (patient 2) & 1 & \\
Unusual coronary anatomy & 2 & 5.0 \\
Abnormal EST or MPI (patients 4, 6) & 2 & 5.0 \\
ASD closure & 1 & 2.5 \\
\hline
\end{tabular}

ASD, atrial septal defect; VF, ventricular fibrillation. *Asymptomatic at outpatient visits. Other abbreviations as in Table 1.

Laboratory). MPI was performed with technetium-99 m sestamibi injection, and perfusion imaging was obtained before and after exercise. Studies were read by a radiologist specialized in nuclear medicine. All cardiac catheterizations and angiograms were reviewed by W.R., Director of the Cardiac Catheterization Laboratory. All study results and original images were presented and carefully discussed in a weekly Multidisciplinary Case Conference at Nemours Cardiac Center for final consensus among the group, which included all attending cardiologists, intensivists, surgeons, and anesthesiologists prior to any critical decisions being made.

\section{Results}

The demographic features of the 97 patients are listed in Table 1. Sixty-five percent of the cohort was male, and nearly $70 \%$ had d-TGA with intact ventricular septum. Total duration of follow-up ranged from 1.0 to 25.6 years (median, 8.25 years). All patients had ECG and echocardiogram at regular outpatient clinic visits. Seventy patients $(72.2 \%)$ underwent more than 1 cardiac catheterization after ASO for hemodynamic assessment and/or interventional procedures. Thirty patients had EST, and 24 patients had both EST and MPI.

Coronary artery anatomy was investigated in 40 patients with angiography $(n=39)$ or autopsy $(n=1)$. Of the 39 patients, 24 underwent selective coronary angiography and 15 underwent neoaortic root angiography if deemed adequate for coronary assessment. The major indications for cardiac catheterization included (1) significant hemodynamic abnormalities detected on echocardiogram, (2) routine assessment of hemodynamic status and coronary arteries prior to allowing competitive sports in early adolescence, and (3) heart-related symptoms (Table 2). Only 2 of the 97 patients complained of symptoms during routine outpatient follow up: 1 patient with chest pain was identified to have non-cardiac chest pain (musculoskeletal chest pain), and the other patient with palpitations was demonstrated to have benign isolated monomorphic ventricular ectopies that were suppressed by exercise (patient 5). Two life-threatening events occurred unexpectedly outside the hospital. None of these 40 patients was receiving cardiac medications.

Eleven patients $(11.3 \%)$ were found to have coronary artery abnormalities. Seven patients (patients 1-7; Tables 3,4) had significant coronary artery abnormalities including the 2 patients who presented with unexpected sudden life-threatening events; 1 died suddenly at home (patient 1 ) and the other unexpectedly 


\begin{tabular}{|c|c|c|c|c|c|c|c|c|}
\hline $\begin{array}{l}\text { Patient } \\
\text { ID no. }\end{array}$ & Sex & $\begin{array}{l}\text { Age (years) } \\
\text { at diagnosis } \\
\text { of coronary } \\
\text { lesion }\end{array}$ & Symptoms & $\begin{array}{c}\text { Initial } \\
\text { diagnosis }\end{array}$ & $\begin{array}{l}\text { Original } \\
\text { coronary } \\
\text { anatomy }\end{array}$ & $\begin{array}{l}\text { Initial } \\
\text { operation }\end{array}$ & $\begin{array}{l}\text { Acquired coronary } \\
\text { abnormalities }\end{array}$ & $\begin{array}{l}\text { Coronary } \\
\text { revision }\end{array}$ \\
\hline 1 & $M$ & 3.8 & Sudden death* & d-TGA/IVS & Usual & ASO/LM & $\begin{array}{c}\text { Severe stenosis of LCA } \\
\text { ostium }\end{array}$ & NA \\
\hline 2 & $\mathrm{~F}$ & 9.6 & $\begin{array}{l}\text { Cardiac arrest/ } \\
\text { VF* }^{*}\end{array}$ & d-TGA, VSD & Usual & $\begin{array}{l}\text { ASO/LM; VSD } \\
\text { closure }\end{array}$ & $\begin{array}{c}\text { Severe stenosis of LCA } \\
\text { ostium }\end{array}$ & Yes \\
\hline 3 & M & 12.6 & None & d-TGA/IVS & Usual & ASO/LM & $\begin{array}{l}\text { Moderate stenosis of LCA } \\
\text { ostium }\end{array}$ & Yes \\
\hline 4 & M & 9.5 & None & d-TGA/IVS & LCX from RCA & ASO/LM & $\begin{array}{l}\text { Complete obliteration of } \\
\text { proximal LAD; } \\
\text { Retrograde filling by RCA } \\
\text { via collateral vessels }\end{array}$ & Yes \\
\hline 5 & M & 15 & $\begin{array}{l}\text { Palpitation } \\
\text { (Isolated PVC) }\end{array}$ & d-TGA/IVS & $\begin{array}{l}\text { Dominant RCA; } \\
\text { Collateral flow } \\
\text { to hypoplastic } \\
\text { LCX, small LAD }\end{array}$ & ASO/LM & Total obliteration of LCX & No \\
\hline 6 & M & 0.6 & None & d-TGA/IVS & Usual & ASO/LM & Total obliteration of LCA & No \\
\hline 7 & M & 10.3 & None & d-TGA/IVS & $\begin{array}{l}\text { Single coronary } \\
\text { artery }\end{array}$ & $\begin{array}{c}\text { ASO/LM; } \\
\text { Takeuchi } \\
\text { procedure }^{\dagger}\end{array}$ & $\begin{array}{c}\text { Obliteration of proximal RCA } \\
\text { RCA supplied by } \\
\text { collaterals from proximal } \\
\text { and distal LCA }\end{array}$ & No \\
\hline
\end{tabular}

${ }^{*}$ Asymptomatic at outpatient visits. ${ }^{\dagger}$ Creation of an aortopulmonary window and intra-PA baffling connecting the aorta to the single coronary artery. ASO, arterial switch operation; LCA, left coronary artery; LCX, left circumflex artery; LM, LeCompte maneuver; NA, not applicable; PA, pulmonary artery; PVC, premature ventricular complex; RCA, right coronary artery. Other abbreviations as in Tables 1,2.

\begin{tabular}{|c|c|c|c|c|c|c|}
\hline $\begin{array}{l}\text { Patient } \\
\text { ID no. }\end{array}$ & ECG & Echocardiogram & EST & MPI & MRI & Outcome \\
\hline 1 & NSR, WNL & $\begin{array}{c}\text { Normal RV, LV function; } \\
\text { Branch PA not well } \\
\text { visualized }\end{array}$ & ND & ND & $\begin{array}{l}\text { Slight narrowing of RPA; } \\
\text { Coronary not delineated } \\
\text { (3.25 years) }\end{array}$ & $\begin{array}{l}\text { Sudden death } \\
\text { (3.75 years) }\end{array}$ \\
\hline 2 & NSR, WNL & $\begin{array}{l}\text { Mild RV enlargement, } \\
\text { Moderate neo-PI; Mild } \\
\text { neo-Ao dilatation }\end{array}$ & Normal & Normal & ND & Alive \\
\hline 3 & NSR, RBBB & $\begin{array}{l}\text { Mild RV enlargement, } \\
\text { mild branch PA stenosis, } \\
\text { mild-moderate neo PI }\end{array}$ & Normal & Normal & $\begin{array}{l}\text { Significant narrowing } \\
\text { of LCA orifice }\end{array}$ & Alive \\
\hline 4 & NSR, RBBB & $\begin{array}{c}\text { Trivial supravalvar } \\
\text { neo-PS }\end{array}$ & $\begin{array}{l}\text { Max } \mathrm{VO}_{2} 65 \% \text { predicted } \\
\text { ST-T depression }(7 \mathrm{~mm}) \\
\text { in lateral leads }\end{array}$ & $\begin{array}{l}\text { Reversible } \\
\text { perfusion } \\
\text { defect }\end{array}$ & ND & Alive \\
\hline 5 & $\begin{array}{l}\text { NSR, } 1^{\circ} \text { AVB; } \\
\text { Isolated PVC }\end{array}$ & Mild-moderate neo-AI & $\begin{array}{c}\text { Max } \mathrm{VO}_{2} 72 \% \text { predicted } \\
\text { isolated PVC suppressed } \\
\text { by exercise }\end{array}$ & Normal & $\begin{array}{l}\text { Mild dilatation of neo-Ao, } \\
\text { mild biventricular } \\
\text { dilatation, LCA not } \\
\text { well seen }\end{array}$ & Alive \\
\hline 6 & NSR, RVH & $\begin{array}{l}\text { Mild MPA stenosis, } \\
\text { mild neo-Al }\end{array}$ & ND & ND & ND & $\begin{array}{l}\text { Lost to } \\
\text { follow-up }\end{array}$ \\
\hline 7 & NSR, IRBBB & $\begin{array}{c}\text { Free neo-PI (s/p } \\
\text { transannular patch } \\
\text { augmentation of RVOT } \\
\text { at } 3 \text { months) }\end{array}$ & $\begin{array}{l}\text { ST-T depression }(2 \mathrm{~mm}) \\
\text { in lateral leads }\end{array}$ & Normal & $\begin{array}{l}\text { Moderate RV dilation, } \\
\text { mild proximal RPA } \\
\text { narrowing, delayed Gd } \\
\text { enhancement of LV } \\
\text { endocardium }\end{array}$ & Alive \\
\hline
\end{tabular}

$1^{\circ} \mathrm{AVB}$, first-degree atrioventricular block; Gd, gadolinium; IRBBB, incomplete right bundle branch block; LV, left ventricle; MPI, myocardial perfusion imaging; ND, not done; neo-Al, neo-aortic insufficiency; neo-Ao, neo-aorta; neo-PI, neo-pulmonary insufficiency; neo-PS, neopulmonary stenosis; NSR, normal sinus rhythm; RBBB, right bundle branch block; RPA, right pulmonary artery; RV, right ventricle; RVH, right ventricular hypertrophy; RVOT, right ventricular outflow tract; $s / p$, status post; WNL, within normal limits. Other abbreviations as in Tables $1-3$.

developed ventricular fibrillation (VF) during exercise (patient 2). Four patients (patients 8-11), all asymptomatic, were found to have only minor coronary anomalies on selective coronary angiogram (Table S1). Nine patients were totally asymptomatic at the routine outpatient visits, but 5 of these were found to have significant coronary artery abnormalities on coronary angiogram (patients 3-7). Four patients had complete obliteration of one of the coronary artery branches (left anterior descending artery [LAD], $\mathrm{n}=2$; left circumflex artery [LCX], $\mathrm{n}=1$; and right coronary artery $[\mathrm{RCA}], \mathrm{n}=1$ ) with retrograde filling via collateral vessels from the contra-lateral side. One asymptomatic patient had EST and MPI abnormalities (patient 

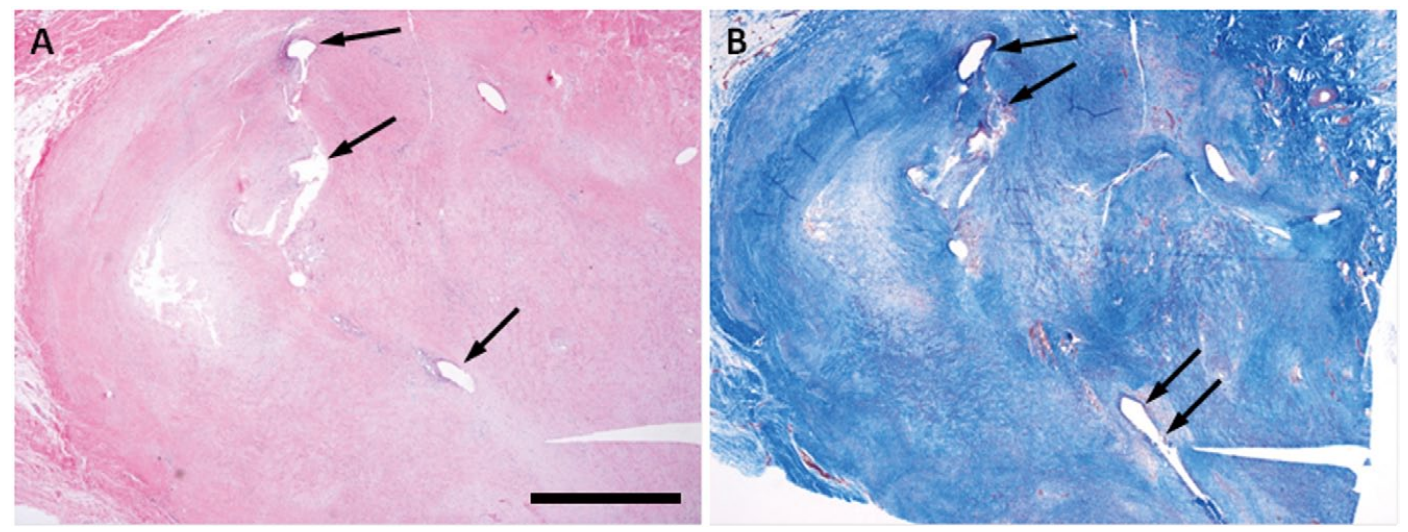

Figure 1. Cross-sectional micrographs of the left coronary artery ostium in patient 1: (A) hematoxylin-eosin staining and (B) Masson's trichrome staining. There is extensive intimal thickening with prominent intimal fibrosis (B, blue) with severely obliterated vascular lumens (arrows). Scale bar, $500 \mu \mathrm{m}$.
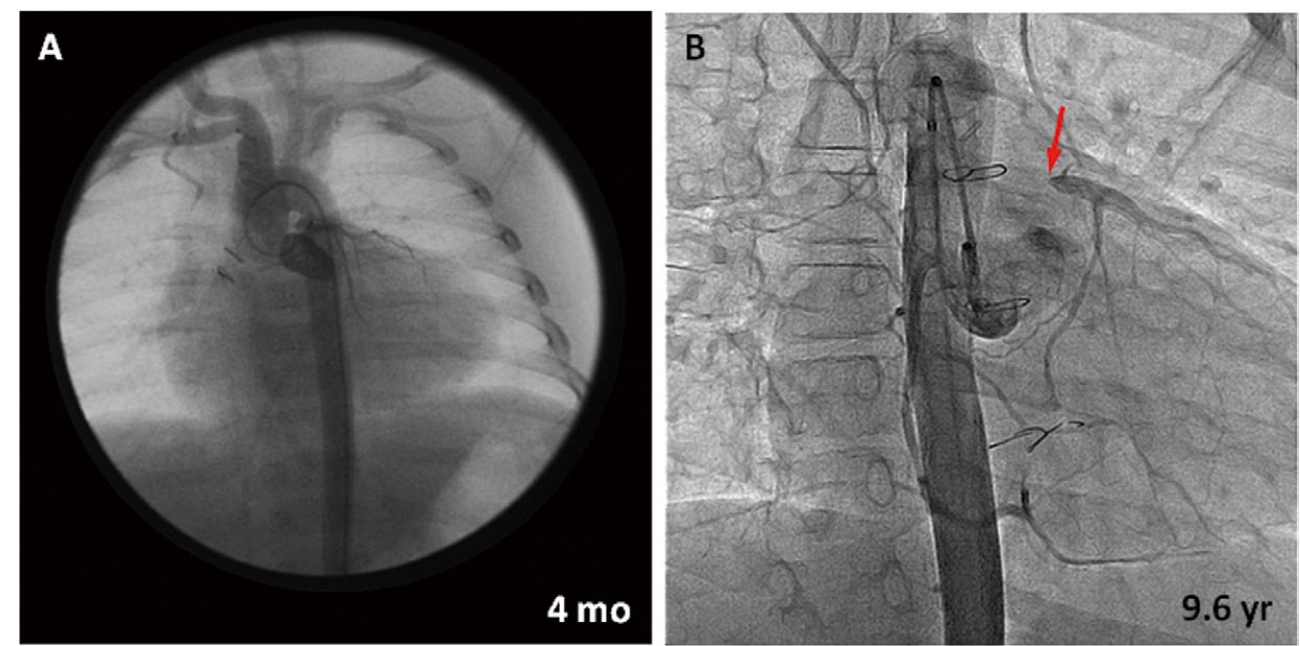

Figure 2. Aortic root injection in patient 2 at (A) 4 months and (B) soon after the patient developed near-fatal ventricular fibrillation, at 9.6 years. The orifice of the left main coronary artery is severely narrowed (arrow).

4), and 4 patients (patients 2,3,5,7) had negative EST and MPI despite significant stenosis or total occlusion of one of the major coronary arteries (Table 4). MRI and CT/CT angiogram were performed mainly to assess the anatomy of great vessels inadequately visualized on echocardiogram. MRI detected significant narrowing of the left coronary artery (LCA) orifice in patient 3.

Patient 1 underwent ASO with no significant postoperative complications. At 3 years of age, he presented at the outpatient clinic with normal physical examination without symptoms and normal echocardiographic findings except for mild bilateral branch PA stenosis. MRI confirmed mild narrowing of the PAs but could not delineate coronary artery anatomy. Seven months after this visit, he died suddenly at home after complaining of acute onset of abdominal pain followed by a generalized seizure. Autopsy demonstrated severe ostial stenosis of the LCA with near-complete luminal obliteration by severe intimal fibrosis (Figure 1).

Patient 2 had ASO and patch repair of perimembranous type ventricular septal defect in the newborn period. At 4 months of age, she underwent surgical revision of residual right ventricular outflow tract (RVOT) obstruction. Aortic root injection at preoperative cardiac catheterization showed unobstructed coronary arteries (Figure 2A). After the surgical RVOT revision, she did well clinically with no symptoms. Echocardiography showed mild residual pulmonary stenosis (PS) and insufficiency with mild RV dilatation. At 8.7 years of age, she had negative EST and MPI with excellent fitness level. Ten months later, however, she had a cardiac arrest during a lacrosse game due to VF. Aortic root injection showed severe stenosis of the LCA ostium (Figure 2B). Intraoperative observation showed that the LCA ostium was severely stenotic and par- 

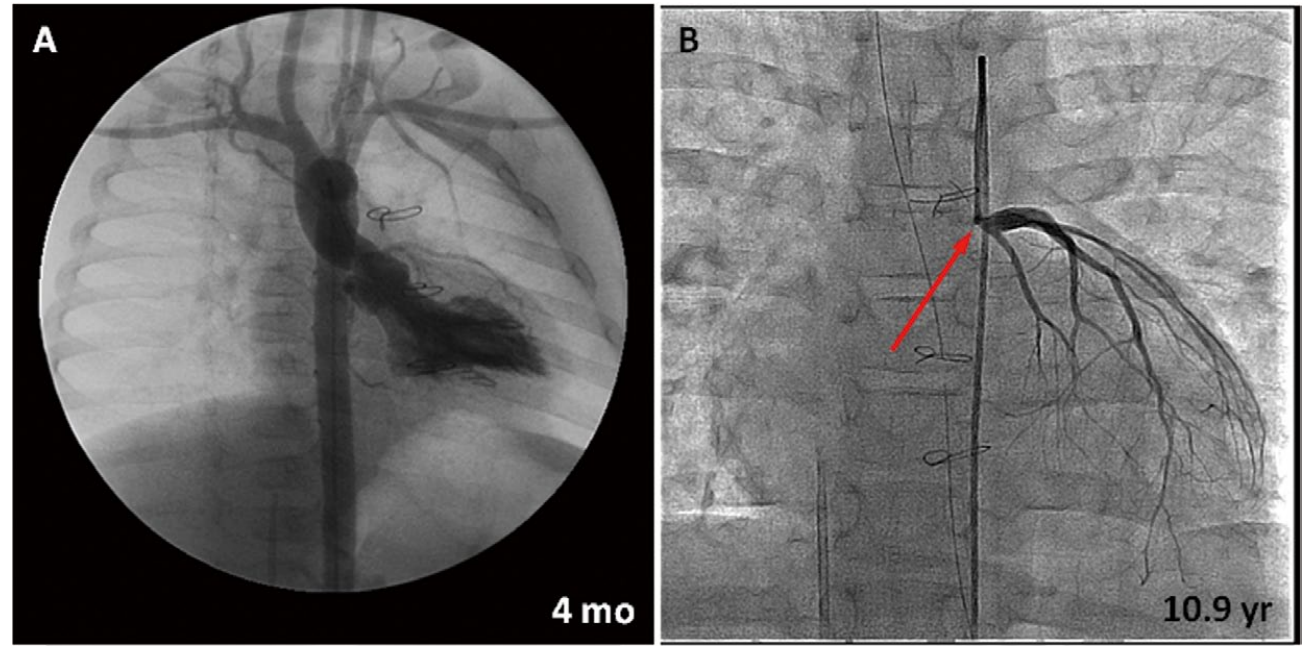

Figure 3. Elective left ventriculogram and selective coronary angiogram at (A) 4 months and (B) 10.9 years, respectively, in patient 3. Although there was no narrowing at the proximal left main coronary artery (LCA) earlier, there was moderate stenosis of the proximal LCA later on (arrow).
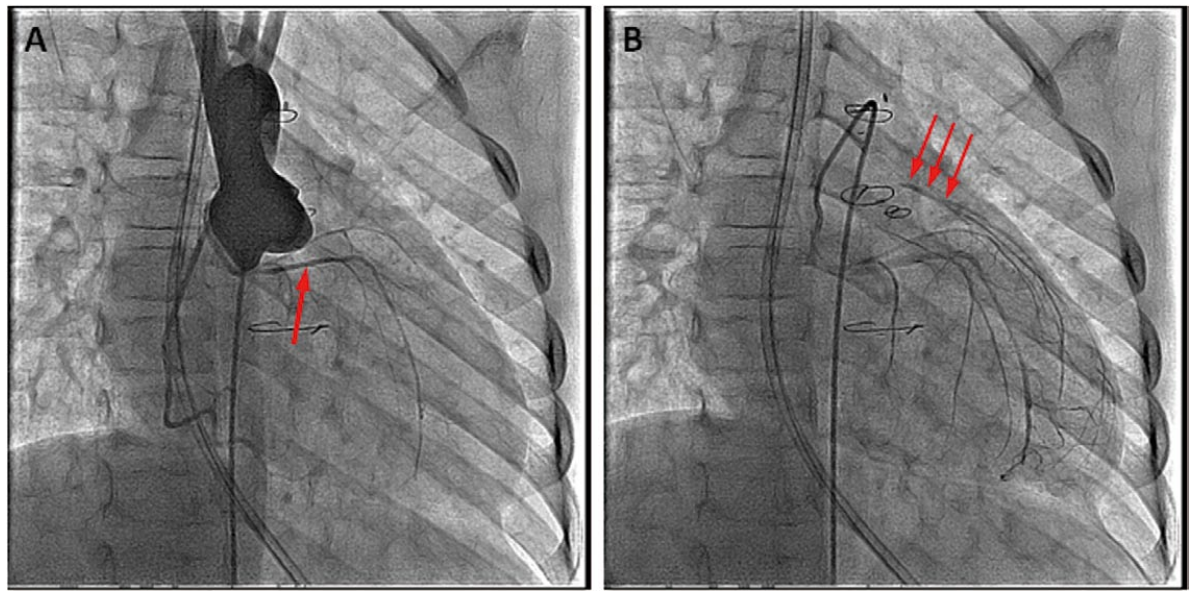

Figure 4. Coronary angiogram of patient 4 at 9 years of age. (A) On aortic root injection, the right coronary artery (RCA) is shown to give rise to left circumflex artery (LCX; arrow), but the left anterior descending artery (LAD) is not filled from the aorta, suggesting possible complete obliteration of the proximal LAD. (B) Selective RCA angiogram showing that the LAD (arrows) is filled retrograde from the LCX via collateral vessels.

tially covered with a flap of intima. She underwent pericardial patch augmentation of the left main coronary artery without significant postoperative complications. There was no recurrence of VF after the coronary artery revision.

Patient 3 had surgical revision of supravalvar PS (mean pressure gradient on echocardiogram, $30 \mathrm{mmHg}$ ) and supravalvar aortic stenosis (mean pressure gradient, $28 \mathrm{mmHg}$ ) 4 months after ASO. Cardiac catheterization at 4 months of age showed mild bilateral residual branch PS with no abnormal findings in the coronary arteries (Figure 3A). EST and MPI at 11 years of age showed no abnormal findings with good exercise effort and normal aerobic fitness level for his age. Routine cardiac catheterization at 12 years of age, however, indicated moderate ostial stenosis of the LCA on selective coronary angiogram (Figure 3B). The coronary lesion was thought to be progressive when compared with the previous angiogram (Figure 3A). The patient underwent coronary revascularization surgery with pericardial patch augmentation of left main ostial stenosis with an uneventful postoperative course.

Patient 4 had an LCX originating from the RCA. After initial ASO, he underwent homograft patch augmentation of the main PA and right PA at 9 months of age. Left ventricle injection suggested unobstructed coronary arteries, but aortic root or selective coronary injection was not performed. The patient 
had routine EST and MPI at 9 years of age prior to participating in competitive sports. There were no symptoms induced by exercise, but his fitness level was mildly diminished. At the peak of exercise, ECG showed significant exercise-induced ST-T depression $(7 \mathrm{~mm})$ in the lateral leads with simultaneous MPI showing exercise-induced perfusion defect at the apex and the anteroseptal wall. Subsequent selective coronary angiography showed complete obliteration of the proximal LAD with collateral supply from small distal LCX and RCA (Figure 4). He underwent revascularization surgery of the occluded proximal LAD at another institution. Three other asymptomatic patients (patients 5, 6, and 7) were found to have total obliteration of 1 coronary artery supplied by collateral vessels originating from the other coronary artery.

None of these 7 patients had specific symptoms referable to myocardial ischemia. The significant coronary abnormalities were not detected until coronary angiography was performed or the patient presented with life-threatening conditions. MRI had limited value in determining coronary abnormality in the present series (Tables 3,4).

\section{Discussion}

Coronary artery abnormalities, including stenosis, significant obstruction, or complete obliteration, are known as early and late complications after ASO. The incidence of late coronary abnormalities has not been well documented, because the reported incidences tend to depend upon the intensity of the specific coronary investigations. Patients with late coronary artery abnormalities after ASO are commonly asymptomatic, with no evidence of myocardial ischemia on routine outpatient testing. ${ }^{7,18,23}$ Only sporadic cases of angiogram-proven coronary abnormalities or unexpected sudden death with postmortem evidence of coronary artery occlusion have been reported. ${ }^{11,13,21,24}$ This may not reflect the entire clinical spectrum of abnormal coronary artery changes occurring late after the initial ASO. Herein, we report on 11 (11.3\%) of 97 post-ASO patients who developed variable degrees of late coronary artery abnormalities; of these, 7 (7.2\%) had significant coronary vascular changes including total obliteration. These numbers are probably underestimating the true incidence, because only $40 \%$ of the present post-ASO patients underwent diagnostic coronary angiography (39 of 97).

Several mechanisms have been implicated as contributing factors to the development of coronary artery occlusion, including fibrosis of the suture line surrounding the coronary ostium, mechanical kinking and stretching of the transplanted vessels, and reactive injury related to the surgical procedure. ${ }^{17}$ The spatial relationship between the coronary arteries and great vessels after ASO may predispose the coronary arteries to the development of late vascular stenosis. ${ }^{25}$ The presence of intimal thickening after ASO suggests a specific underlying condition that favors development of vascular remodeling. ${ }^{26,27}$ Pedra et al reported that $50 \%$ of 22 children were found to have proximal eccentric intimal thickening on intravascular ultrasound after ASO ${ }^{27}$ We observed similar pathological findings in the present patients 1 and 2, which may represent extreme-spectrum post-ASO vascular remodeling. The underlying pathogenesis of intimal thickening remains poorly understood. Acute angle of the coronary origin has been observed frequently with neoaortic root dilatation, ${ }^{28}$ particularly in adults late after ASO. ${ }^{29}$ The underlying mechanisms of coronary artery obstruction after ASO are multifold.

The present patients represent a wide variation in the clinical spectrum of acquired coronary artery problems after ASO, from unexpected sudden death at rest and near-fatal exerciseinduced VF to totally asymptomatic condition with trivial abnormality in coronary arterial architecture. All of the present 7 patients with significant coronary abnormalities were clinically asymptomatic at the outpatient follow up visit. Importantly, none of these coronary abnormalities was detected on history and/or non-invasive studies including ECG and echocardiogram, and only 1 patient had positive screening on EST and MPI (patient 4). Although Khairy et al recently reported a relatively low incidence of late coronary complications after ASO in a larger single-center study,${ }^{30}$ the present results suggest that an occurrence of late coronary events including sudden cardiac death is not insignificant and consistent with the reports by other groups. ${ }^{18,20,31}$ Whereas the clinical significance of trivial-mild coronary abnormalities is not entirely clear, some coronary vascular changes may be progressive. ${ }^{20}$ PostASO coronary artery abnormalities may not be detected reliably without specific coronary imaging. ${ }^{16}$ It is misleading to assume that lack of clinical symptoms affirms absence of potentially lethal coronary abnormalities that may lead to myocardial ischemia, catastrophic ventricular arrhythmia, or even sudden death. Based upon our experience, we have changed our practice to include assessment for coronary abnormalities after ASO, regardless of physical symptoms. We now routinely perform coronary angiography (preferably selective coronary angiogram) in addition to EST and/or MPI before patients reach the age of participation in competitive sports (usually before age 12). We also frequently perform coronary angiography (or at least neoaortic root injection) in patients who are undergoing diagnostic or interventional cardiac catheterization for other residual hemodynamic abnormalities.

We found that EST as a screening test for coronary insufficiency after ASO is neither sensitive nor specific. One nearfatal false-negative result was seen in patient 2, whereas 3 false-positive EST changes were confirmed on coronary angiogram (data not shown), given that ST-T segment depression does not necessarily indicate myocardial ischemia in children. ${ }^{32}$ EST is a useful non-invasive tool in assessing aerobic fitness level and in identifying the nature of exercise-induced symptoms and/or arrhythmias, but its reliability in detecting occult myocardial ischemia after ASO appears to be limited in children and adolescents. Perfusion defects on MPI have been reported in asymptomatic patients after ASO, but the clinical significance has not been well determined in children. ${ }^{33}$ Although MPI was true positive for myocardial ischemia in patient 4 , the negative studies cannot always rule out the presence of silent myocardial ischemia or significant coronary abnormalities (stenosis/occlusion) in the pediatric population (patients 2,3). MPI has a limited role in detecting underlying coronary abnormalities. ${ }^{34}$ Based upon the present data, we emphasize that coronary imaging, especially selective coronary angiography, may be considered as a routine follow-up investigation for late coronary abnormality, as advocated by other groups. ${ }^{12,14}$ At a minimum, those patients with significant coronary abnormalities merit either further coronary revascularization intervention or closer outpatient monitoring under certain exercise restriction.

Although coronary angiography is regarded as the gold standard in assessing coronary artery anatomy, there are several technical challenges for delineation of coronary anatomy after ASO. The location of coronary artery orifices varies after ASO and is not in the position for which the standard coronary catheters are designed. In addition, mismatch between aortic root and ascending aorta sizes complicates catheter curve selection. In most cases, non-standard coronary catheters and/ 
or manual reshaping are necessary. Proper catheter position and injection techniques are critical for optimum opacification of the orifice where most stenoses are located. ${ }^{23}$ Projection angles have to be customized to delineate the orifice and proximal coronary artery segment. These crucial points should be addressed properly to be able to generate a reliable coronary angiogram. CT angiography may be a good alternative for coronary angiography in patients with appropriate heart rates and when state-of-the-art multislice scanners are available. Ou et al. addressed certain advantages of CT angiography over coronary angiography: it allows (1) visualization of topographic context of adjacent structures, (2) multiple viewing angles, and (3) better visualization of coronary ostia or proximal segments. ${ }^{25,35}$

Overall myocardial perfusion status after ASO may depend on the degree of vascular occlusion and simultaneous collateral vessel formation. Two of the present patients with severe LCA stenosis presented with serious life-threatening conditions, whereas patients with total LCA occlusion remained asymptomatic in the setting of collateral vessel formation. These asymptomatic patients with complete obliteration of 1 vessel and concomitant collateral vessel formation may still be at risk at times of extreme myocardial demand and/or when atherosclerotic changes develop. ${ }^{17}$ Surgical intervention may be indicated for those who are symptomatic or who have clinical evidence of myocardial ischemia. The clinical significance of trivial-mild coronary abnormalities after ASO remains unknown. It is possible that this is a static minor vascular abnormality, but it could also represent as an early phase of progressive vascular remodeling. ${ }^{20}$ Although these relatively minor coronary abnormalities are unlikely to develop into lethal events, we recommend careful long-term follow-up of patients who develop coronary artery problems after ASO.

\section{Study Limitations}

This was a retrospective chart review in a single center, and thus, the number of patients studied was limited. In addition, during this period of time, cardiologists had varied practices for assessing patients with d-TGA after ASO. Also, use of cardiac catheterization and coronary angiography was not consistent among the cardiologists at Nemours Cardiac Center. Only a limited number of asymptomatic patients had routine coronary angiography. Thus, the true incidence of acquired coronary abnormalities may be higher in the present patients following ASO.

\section{Conclusions}

Late coronary artery abnormality is not a rare complication after ASO. Clinical presentation may be altered by the presence or absence of collateral vessels and the status of myocardial sympathetic denervation/reinnervation after transsection of the great arteries during ASO. ${ }^{36}$ Patients with this abnormality may be asymptomatic until they present with catastrophic life-threatening events. Based upon our experience, and as advocated by others, ${ }^{10,20}$ we recommend coronary angiography or coronary $\mathrm{CT}$ angiography to rule out preclinical coronary abnormalities after ASO. Whether repeated coronary imaging at regular intervals is warranted remains to be determined.

\section{Conflict of Interest}

None.

\section{References}

1. Brown JW, Park HJ, Turrentine MW. Arterial switch operation: Factors impacting survival in the current era. Ann Thorac Surg 2001; 71: $1978-1984$.

2. Daebritz SH, Nollert G, Sachweh JS, Engelhardt W, von Bernuth G, Messmer BJ. Anatomical risk factors for mortality and cardiac morbidity after arterial switch operation. Ann Thorac Surg 2000; 69: 18801886.

3. Qamar ZA, Goldberg CS, Devaney EJ, Bove EL, Ohye RG. Current risk factors and outcomes for the arterial switch operation. Ann Thorac Surg 2007; 84: 871 -878; discussion 878-879.

4. Rudra HS, Mavroudis C, Backer CL, Kaushal S, Russell H, Stewart $\mathrm{RD}$, et al. The arterial switch operation: 25-year experience with 258 patients. Ann Thorac Surg 2011; 92: 1742-1746.

5. Popov AF, Tirilomis T, Giesler M, Oguz Coskun K, Hinz J, Hanekop GG, et al. Midterm results after arterial switch operation for transposition of the great arteries: A single centre experience. J Cardiothorac Surg 2012; 7: 83.

6. Fricke TA, d'Udekem Y, Richardson M, Thuys C, Dronavalli M, Ramsay JM, et al. Outcomes of the arterial switch operation for transposition of the great arteries: 25 years of experience. Ann Thorac Surg 2012; 94: 139-145.

7. Legendre A, Losay J, Touchot-Kone A, Serraf A, Belli E, Piot JD, et al. Coronary events after arterial switch operation for transposition of the great arteries. Circulation 2003; 108(Suppl 1): II186-II190.

8. Blume ED, Altmann K, Mayer JE, Colan SD, Gauvreau K, Geva T. Evolution of risk factors influencing early mortality of the arterial switch operation. J Am Coll Cardiol 1999; 33: 1702-1709.

9. Prifti E, Crucean A, Bonacchi M, Bernabei M, Murzi B, Luisi SV, et al. Early and long term outcome of the arterial switch operation for transposition of the great arteries: Predictors and functional evaluation. Eur J Cardiothorac Surg 2002; 22: 864-873.

10. Pretre R, Tamisier D, Bonhoeffer P, Mauriat P, Pouard P, Sidi D, et al. Results of the arterial switch operation in neonates with transposed great arteries. Lancet 2001; 357: 1826-1830.

11. Hutter PA, Kreb DL, Mantel SF, Hitchcock JF, Meijboom EJ, Bennink GB. Twenty-five years' experience with the arterial switch operation. J Thorac Cardiovasc Surg 2002; 124: 790-797.

12. Hutter PA, Bennink GB, Ay L, Raes IB, Hitchcock JF, Meijboom EJ. Influence of coronary anatomy and reimplantation on the longterm outcome of the arterial switch. Eur J Cardiothorac Surg 2000; 18: $207-213$.

13. Wong SH, Finucane K, Kerr AR, O'Donnell C, West T, Gentles TL. Cardiac outcome up to 15 years after the arterial switch operation. Heart Lung Circ 2008; 17: 48-53.

14. Angeli E, Formigari R, Pace Napoleone C, Oppido G, Ragni L, Picchio FM, et al. Long-term coronary artery outcome after arterial switch operation for transposition of the great arteries. Eur J Cardiothorac Surg 2010; 38: 714-720.

15. Lalezari S, Bruggemans EF, Blom NA, Hazekamp MG. Thirty-year experience with the arterial switch operation. Ann Thorac Surg 2011; 92: $973-979$.

16. Tobler D, Williams WG, Jegatheeswaran A, Van Arsdell GS, McCrindle BW, Greutmann M, et al. Cardiac outcomes in young adult survivors of the arterial switch operation for transposition of the great arteries. J Am Coll Cardiol 2010; 56: 58-64.

17. Tanel RE, Wernovsky G, Landzberg MJ, Perry SB, Burke RP. Coronary artery abnormalities detected at cardiac catheterization following the arterial switch operation for transposition of the great arteries. Am J Cardiol 1995; 76: $153-157$.

18. El-Segaier M, Lundin A, Hochbergs P, Jogi P, Pesonen E. Late coronary complications after arterial switch operation and their treatment. Catheter Cardiovasc Interv 2010; 76: 1027-1032.

19. Angeli E, Raisky O, Bonnet D, Sidi D, Vouhe PR. Late reoperations after neonatal arterial switch operation for transposition of the great arteries. Eur J Cardiothorac Surg 2008; 34: 32-36.

20. Raisky O, Bergoend E, Agnoletti G, Ou P, Bonnet D, Sidi D, et al. Late coronary artery lesions after neonatal arterial switch operation: Results of surgical coronary revascularization. Eur J Cardiothorac Surg 2007; 31: 894-898.

21. Losay J, Touchot A, Serraf A, Litvinova A, Lambert V, Piot JD, et al. Late outcome after arterial switch operation for transposition of the great arteries. Circulation 2001; 104: I121-I126.

22. Villafane J, Lantin-Hermoso MR, Bhatt AB, Tweddell JS, Geva T, Nathan M, et al. D-transposition of the great arteries: The current era of the arterial switch operation. J Am Coll Cardiol 2014; 64: $498-511$.

23. Bonhoeffer P, Bonnet D, Piechaud JF, Stumper O, Aggoun Y, Villain E, et al. Coronary artery obstruction after the arterial switch operation for transposition of the great arteries in newborns. J Am Coll Cardiol 1997; 29: 202-206.

24. Bartoloni G, Bianca S, Patane L, Mignosa C. Pathology of coronary 
narrowing after arterial switch operation: Autopsy findings in two patients who died within 3 months of surgical treatment and review of the literature. Cardiovasc Pathol 2006; 15: 49-54.

25. Ou P, Khraiche D, Celermajer DS, Agnoletti G, Le Quan Sang KH, Thalabard JC, et al. Mechanisms of coronary complications after the arterial switch for transposition of the great arteries. J Thorac Cardiovasc Surg 2013; 145: $1263-1269$.

26. Tsuda E, Imakita M, Yagihara T, Ono Y, Echigo S, Takahashi O, et al. Late death after arterial switch operation for transposition of the great arteries. Am Heart J 1992; 124: 1551 - 1557.

27. Pedra SR, Pedra CA, Abizaid AA, Braga SL, Staico R, Arrieta R, et al. Intracoronary ultrasound assessment late after the arterial switch operation for transposition of the great arteries. J Am Coll Cardiol 2005; 45: 2061-2068.

28. Zanjani KS, Niwa K. Aortic dilatation and aortopathy in congenital heart diseases. J Cardiol 2013; 61: 16-21.

29. Veltman CE, Beeres SL, Kalkman DN, Kelder TP, Kies P, Vliegen $\mathrm{HW}$, et al. Variation in coronary anatomy in adult patients late after arterial switch operation: A computed tomography coronary angiography study. Ann Thorac Surg 2013; 96: 1390-1397.

30. Khairy P, Clair M, Fernandes SM, Blume ED, Powell AJ, Newburger JW, et al. Cardiovascular outcomes after the arterial switch operation for D-transposition of the great arteries. Circulation 2013; 127: 331-339.

31. Bonnet D, Bonhoeffer P, Piechaud JF, Aggoun Y, Sidi D, Planche C, et al. Long-term fate of the coronary arteries after the arterial switch operation in newborns with transposition of the great arteries. Heart 1996; 76: $274-279$.
32. Hovels-Gurich HH, Kunz D, Seghaye M, Miskova M, Messmer BJ, von Bernuth G. Results of exercise testing at a mean age of 10 years after neonatal arterial switch operation. Acta Paediatr 2003; 92: $190-196$.

33. Weindling SN, Wernovsky G, Colan SD, Parker JA, Boutin C, Mone $\mathrm{SM}$, et al. Myocardial perfusion, function and exercise tolerance after the arterial switch operation. J Am Coll Cardiol 1994; 23: 424-433.

34. Sterrett LE, Schamberger MS, Ebenroth ES, Siddiqui AR, Hurwitz RA. Myocardial perfusion and exercise capacity 12 years after arterial switch surgery for D-transposition of the great arteries. Pediatr Cardiol 2011; 32: 785-791.

35. Ou P, Celermajer DS, Marini D, Agnoletti G, Vouhe P, Brunelle F, et al. Safety and accuracy of 64-slice computed tomography coronary angiography in children after the arterial switch operation for transposition of the great arteries. JACC Cardiovasc Imaging 2008; 1: $331-339$.

36. Kondo C, Nakazawa M, Momma K, Kusakabe K. Sympathetic denervation and reinnervation after arterial switch operation for complete transposition. Circulation 1998; 97: 2414-2419.

\section{Supplementary Files}

Supplementary File 1

Table S1. Clinical presentation in 4 patients with minor coronary abnormalities

Please find supplementary file(s);

http://dx.doi.org/10.1253/circj.CJ-15-0485 